\title{
The comparison of assault and falling in elder patients over 65 years of age
}

\author{
Kaan Celik ${ }^{1}$, Tamer Colak ${ }^{1, *}$
}

\author{
${ }^{1}$ Department of Emergency, Faculty of \\ Medicine, Bolu Abant Izzet Baysal \\ University, 14030 Bolu, Turkey

\section{*Correspondence} \\ drtamercolak@gmail.com \\ (Tamer Colak)
}

\begin{abstract}
Objective: The aim of the present study was to determine suspected events for elder abuse, and to increase awareness of the clinicians by comparing traumatic elder abuse and falling.

Methods: The study was conducted retrospectively on individuals older than 65 years referred due to traumatic abuse and falling between 1 June 2014 and 30 September 2019. The patients were evaluated for age, gender, co-morbidity, trauma location, trauma scores at referral [injury severity score (ISS), Glasgow coma scale (GCS)], and vital parameters at referral [mean arterial pressure (MAP), and the pulse rate]. Variable distribution was evaluated by Kolmogorov-Simirnov test. Mann Whitney U test was used for analysis of quantitative data; chi-square test was utilized for analysis of independent qualitative data; Fischer's test was used when chi-square conditions are provided.

Results: The median age of the patients exposed to abuse was 73 (IQR: 11) years and $48 \%$ of these patients were male. The age median of the patients exposed to abuse was significantly higher; frequency of female patients were significantly more $(p<0.05)$. Fracture incidence was higher in the patients who have fallen; however, soft tissue trauma was higher in the patients who have been abused $(p<0.05)$. Hospitalization prevalence of assaulted cases was higher $(p<0.05)$; however, mortality prevalence was similar $(p$ $>0.05)$.

Conclusion: Consequently, abuse causes severe traumas when compared with accident and falling. The probability of abuse should be considered in elder trauma cases with specific locations (upper limbs and face etc.).
\end{abstract}

\section{Keywords}

Elder patient; Elder abuse; Trauma; Emergency

\section{Introduction}

Elder trauma cases commonly refer to emergency department, leading to morbidity and mortality. Some of such trauma cases occur by traffic accident and falling; however, some appear due to abuse [1, 2]. Developments in healthcare and technology have led prolongation of life and increase of elder population. Such rapid increase in elder population has led an increase in incidence of trauma and abuse [3, 4].

It was reported in some manuscripts that abuse prevalence increases up to $20 \%$ after 2010 ; and $10 \%$ to $25 \%$ of such patients were exposed to physical abuse [2, 5-8]. Several types of elder abuse including omission, financial, physical and sexual were identified. Some victims reported that they were exposed to multiple forms of abuse simultaneously $[9,10]$. However, the majority of the victims hide the abuse due to causes including fear of recompense, increase of victimization, fear of eviction and desire to protect the assaulter due to family ties. Furthermore, problems in evaluation and reporting as a result of pathological conditions such as dementia and stroke lead decrease of abuse recognition. In consideration of all these factors, reporting incidence is below $2 \%[2,3]$.

There is limited information about diagnosis incidence of elder abuse or on characteristics of diagnosed patients [11]. It was reported that the patients exposed to abuse referred to emergency department due to falling [12]. Moreover, it was stressed that such falling may be triggered by the abuser or the individual may be pushed [12].

The cases that were assaulted by family members usually express that they have fallen. The aim of the present study was to determine suspicious events for elder abuse and to increase awareness of the clinicians by comparing traumatic elder abuse and falling.

\section{Material and method}

The study was conducted retrospectively on individuals older than 65 years referred due to assault and falling between 1 
June 2014 and 30 September 2019 following approval of local ethical committee of Abant Izzet Baysal University (Date: 21/01/2020; Decision No: 2019/248).

Among the patients older than 65 years, 11,422 were trauma cases including 6839 cases of falling, 1497 cases of assault, 2993 cases of traffic accident and 93 cases of firearm injury. Hospital records of 684 patients were accessed by randomly selecting $10 \%$ of aforesaid 6839 patients referred for falling. Ten percent (10\%) of falling cases were randomly selected and files of 684 patients were accessed. The control group consisted of 671 patients because of deficient data of 13 patients. In the review of patient records, cases over 65 years of age with forensic reports due to assault were enrolled into the study. Forensic and hospital records of all assault cases were accessed and 103 cases were detected as abused. The assault cases other than abuse as well as 2 cases of abuse with deficient data were excluded. The basic logic on comparison of traumatic abuse cases and falling cases over 65 years of age was the fact that actually battered cases reported falling. The medical history, current trauma, and previous trauma history taken from trauma patients are evaluated in detail in emergency case setting of our hospital. Negligence is identified as a forensic case which is obligatory to be notified. Security forces are informed in case of any conflicting situation after medical history taking and physical examination of the patient; and such case is followed as a forensic case.

The patients were evaluated for age, gender, co-morbidity, trauma location, trauma scores at referral [injury severity score (ISS), Glasgow coma scale (GCS)], vital parameters at referral [mean arterial pressure (MAP), and the pulse rate].

All patients below 65 years of age, traffic accident and firearm injury cases above 65 years of age, assault cases who were not abused by their relatives or relative abuse could not be excluded, and the battered cases whose data could not be accessed from the system or patient records were excluded from the study. Furthermore, the patients with hemorrhagic diathesis were excluded due to possible confusion on physical findings.

SPSS 22.0 package program was used for data analysis. Variable distribution was evaluated by Kolmogorov-Simirnov test. Median and interquartile range (IQR) were used for analysis of quantitative data due to non-parametric design of distributions; frequency and ratio were used for analysis of qualitative data. Mann Whitney U test was used for analysis of quantitative data; chi-square test was utilized for analysis of independent qualitative data; Fischer's test was used when chisquare conditions are provided. A $p$ value $<0.05$ was accepted as statistically significant.

\section{Results}

It was detected that $101(0.002 \%)$ of 52,831 cases $(0.002 \%$ of 52,831 patients over 65 years of age) referred to our emergency department between the determined dates were elder abuse cases. No recurrent referral was detected. The median age of the patients exposed to abuse was 73 (IQR: 11 ) years and $48 \%$ of these patients were male. The median age of the patients referred because of falling was 71 (IQR: 9) and $62.6 \%$ of the cases were male. The age median of the patients exposed to abuse was significantly higher; frequency of female patients were significantly more $(p<0.05)$. Co-morbidity, diabetes mellitus (DM) incidence, cardiovascular disease frequency and stroke frequency were significantly higher in the patients exposed to abuse $(p<0.05)$. The injury frequency on head/neck, face, chest, abdomen and upper limbs was higher in the abused patients whereas the injury frequency on lower limbs was significantly higher in those referring due to falling $(p<0.05)$. Fracture incidence was higher in the patients who have fallen; however, soft tissue trauma was higher in the patients who have been abused $(p<0.05)$. ISS was higher and GCS was lower in the abused patients $(p<0.05)$. There was not any difference in terms of MAP and pulse rate between the groups ( $p>0.05)$. Hospitalization rate due to trauma was $21.8 \%$ and mortality rate was $8.4 \%$. Hospitalization rate was higher in abused patients $(p<0.05)$; and there was not any significant difference for mortality between the groups $(p>0.05)$ (Table 1).

No association was detected between mortality rate and trauma location $(p>0.05)$. ISS was higher and GCS was lower in the patients with mortal progression $(p<0.05)$. There was not any difference for pulse rate and MAP between the groups $(p>0.05)$ (Table 2).

\section{Discussion}

Although distribution of the injuries appeared during physical abuse of the elder has been explained, there is not any convincing evidence to separate those from accidents. Because age-induced modifications such as osteoporosis and cerebral atrophy cause traumatic injuries like falling [3].

Cham et al. [13] reported elder abuse rate as $0.03 \%$ among the cases referred to emergency department. A multi-centered study conducted abroad reported such rate as $0.015 \%$ [2]. The elder abuse rate was detected $1 \%$ in a similar study conducted in our company [14]. The rate in our study was detected $0.002 \%$, similar to previous studies; such rate may be associated with negative behaviors, standards of judgement as well as socio-economic factors that the elders are exposed in the society.

Ozturk et al. [5] and Santos et al. [15] reported a decrease in abuse by increase in age. The median age of the patients abused was detected higher in the present study. This may be related to slight and continuous traumatization of the patients due to increase of dependency by ageing. The decrease of patient rate by ageing in the literature may be associated with the decrease in elder population.

Previous studies reported that female patients were exposed to abuse more [2, 11, 12, 16]. However, Lachs et al. [17] reported no difference of gender in elder abuse cases. In the present study, female patients were exposed to abuse more. This may be related economical dependency of women and being perceived as a burden, more dependency status of women and longer life period of female population. We believe that women are exposed assault more than men due to their physical vulnerability.

The actual cause for elder abuse was shown to be physical and cognitive dysfunction and co-morbid pathologies as actual factors causing these dysfunctions [18, 19]. Evans et al. [2] address that increased co-morbidity and dependent physical 
TA B L E 1. Comparison of demographic and clinical characteristics of falling and abuse cases.

\begin{tabular}{|c|c|c|c|c|}
\hline & & Abuse $(n=101)$ & Falling $(\mathrm{n}=671)$ & $p$ \\
\hline Age, median (IQI & & $73(11)$ & $71(9)$ & 0.02 \\
\hline Gender & Male n (\%) & $48(47.5 \%)$ & $420(62.6 \%)$ & 0004 \\
\hline Gomitiot & Female n $(\%)$ & $53(52.5 \%)$ & $251(37.4 \%)$ & 0.007 \\
\hline & Present, n (\%) & $99(98 \%)$ & $606(90.3 \%)$ & 0.010 \\
\hline & Diabetes mellitus, n (\%) & $61(60.4 \%)$ & $324(48.3 \%)$ & 0.023 \\
\hline & Hypertension, n (\%) & $56(55.4 \%)$ & $317(47.2 \%)$ & 0.124 \\
\hline Comorhidity & Cardiovascular disease, $\mathrm{n}(\%)$ & $68(67.3 \%)$ & $231(34.4 \%)$ & $<0.001$ \\
\hline Comiluiviuity & Dementia/Alzheimer, n (\%) & $10(9.9 \%)$ & $98(14.6 \%)$ & 0.204 \\
\hline & Stroke, n (\%) & $31(30.7 \%)$ & $109(16.2 \%)$ & $<0.001$ \\
\hline & Osteoporosis, n (\%) & $17(16.8 \%)$ & $92(13.7 \%)$ & 0.401 \\
\hline & Other, $\mathrm{n}(\%)$ & $17(16.8 \%)$ & $87(13 \%)$ & 0.289 \\
\hline & Head/neck, n (\%) & $27(26.7 \%)$ & $62(9.2 \%)$ & $<0.001$ \\
\hline & Face, $n(\%)$ & $19(18.8 \%)$ & $4(0.6 \%)$ & $<0.01$ \\
\hline & Chest, n (\%) & $6(5.9 \%)$ & $9(1.3 \%)$ & 0.002 \\
\hline Trauma location & Abdomen, n (\%) & $8(7.9 \%)$ & $2(0.3 \%)$ & $<0.001$ \\
\hline & Upper limbs, n (\%) & $55(54.5 \%)$ & $272(40.5 \%)$ & 0.023 \\
\hline & Lower limbs, n (\%) & $13(12.9 \%)$ & $226(33.7 \%)$ & 0.023 \\
\hline & Vertebra, n (\%) & $2(2 \%)$ & $30(4.5 \%)$ & 0.242 \\
\hline Trauma severity & Soft tissue trauma, n (\%) & $52(51.5 \%)$ & $222(33.1 \%)$ & $<0.001$ \\
\hline 1rauma severity & Fracture, n (\%) & $19(18.8 \%)$ & $266(39.6 \%)$ & $<0.001$ \\
\hline ISS, median (IQR & & $9(8)$ & $8(6)$ & 0.034 \\
\hline GCS, median (IQ & & $15(2)$ & $15(0)$ & 0.010 \\
\hline Pulse (beat $/ \mathrm{min}$ ), & nedian (IQR) & $74(22.5)$ & $73(14)$ & 0.126 \\
\hline Mean arterial pre & sure (mmHg), median (IQR) & $99(19.3)$ & $96.7(10.3)$ & 0.445 \\
\hline Hospitalization, $n$ & $(\%)$ & $22(21.8 \%)$ & $32(4.8)$ & $<0.001$ \\
\hline Mortality, n (\%) & & $8(7.9 \%)$ & $32(4.8)$ & 0.183 \\
\hline
\end{tabular}

IQR, Interquartile range; ISS, Injury severity score; GCS, Glasgow coma scale.

TA B L E 2. Comparison of mortality and clinical characteristics.

\begin{tabular}{|c|c|c|c|c|}
\hline & & Exitus $(n=8)$ & Alive $(n=93)$ & $p$ \\
\hline \multirow{7}{*}{ Trauma location } & Head/neck, n (\%) & $4(50 \%)$ & $23(24.7 \%)$ & 0.205 \\
\hline & Face, $\mathrm{n}(\%)$ & $2(25 \%)$ & $17(8.3 \%)$ & 0.643 \\
\hline & Chest, n (\%) & $1(12.5 \%)$ & $5(5.4 \%)$ & 0.399 \\
\hline & Abdomen, n (\%) & $2(25 \%)$ & $17(6.5 \%)$ & 0.121 \\
\hline & Upper limbs, n (\%) & $4(50 \%)$ & $51(54.8 \%)$ & $>0.999$ \\
\hline & Lower limbs, n (\%) & 0 & $13(12.9 \%)$ & 0.592 \\
\hline & Vertebra, n $(\%)$ & 0 & $2(2.2 \%)$ & $>0.999$ \\
\hline \multicolumn{2}{|c|}{ ISS, median (IQR) } & $43(35)$ & $9(7)$ & $<0.001$ \\
\hline \multicolumn{2}{|c|}{ GCS, median (IQR) } & $7(3)$ & $15(0)$ & $<0.001$ \\
\hline \multicolumn{2}{|c|}{ Pulse (beat/min), median (IQR) } & $74(21)$ & $73(48)$ & 0.584 \\
\hline \multicolumn{2}{|c|}{ Mean arterial pressure $(\mathrm{mmHg})$, median (IQR) } & $89.6(24)$ & $99(19.3)$ & 0.094 \\
\hline
\end{tabular}

ISS, Injury severity score; GCS, Glasgow coma scale. 
limitations cause the increase of abuse. It was reported that dementia and depression specifically excite the abusers more and they behave more aggressively $[20,21]$. In the present study, comorbidity rate was higher in the patients abused; and DM, cardiovascular diseases (CVD) and stroke rates were higher in the abused patients in the co-morbidity subgroup. We believe that some causes such as bedsores, care of the diabetic foot in DM, some stroke patients living bedridden lead these individuals to become more dependent; and frequent referral to hospital is perceived as a burden by family members causing an increase in frequency of abuse.

The most common geriatric trauma form was stated as traffic accident in the literature; and the most injured area is head/neck with the most common diagnosis as soft tissue trauma [14, 22]. Rosen et al. [12] expressed in their study that the most common area injured in elder abuse cases was the upper limb; injuries of the face and upper limb should alert for any possible abuse. Oztur et al. [5] reported the most common injuries were thorax and head/neck in their study where abuse of the individuals above 65 years of age. It was stated in the aforesaid study that incidence of upper limb injury was more than lower limb. Frazao et al. [16] and Gionda et al. [11] reported in their studies on abused elder patients that the most common injured area was head/neck, followed by upper limb. Santos et al. [15] detected higher injury rates on head and neck. Murphy et al. [3] reported that the most common trauma was detected on upper limbs (44\%) and maxillofacial area (23\%) among the elder patients abused. Trauma of head/neck, face and upper limbs is the most common injury detected in the patient exposed to abuse; injuries of head/neck, face, thorax, abdomen and upper limbs were common in abused cases whereas injury of the lower extremity was more in fallen cases. We believe that victims of the abuse are usually slapped or hit on the face and upper limbs are injured due to use of the arms for selfprotection. The injury rate might have increased since the abuser increase the violence and kick the abdomen and chest. The rate of femur neck injury might have increased on lower limbs due to osteoporosis in falling cases.

Ozturk et al. [5] mentioned that injury of the internal organs is frequent in abuse and simple trauma may result with severe injuries. However, Abath et al. [23] reported that majority of the injuries on upper limb are mild. Murphy et al. [3] expressed that the traumas detected in elders exposed to abuse were superficial injuries on inner sides of the arms. In the present study, soft tissue trauma frequency was detected more in the abused patients; and the fracture frequency was less than those who have fallen. Furthermore, ISS was higher and GCS scores were lower in those who were abused; however, vital parameters did not significantly change. We believe that since the violence is mild but persistent during abuse, the prevalence of soft tissue trauma and fractures of small bone is less. Majority of such mild traumas may not reflect to the hospital and the victim is taken to the hospital when she/he is injured severely. Therefore, lower GSC scores and higher ISS may be explained. Furthermore, GCS may be lower due to intracranial bleeding as a result of fragile blood vessels because the abuser usually hit the victim on the head.

Ozturk et al. [5] reported in their study that $37.8 \%$ of the cases of abuse over 65 years of age are treated by hospital- ization and such rate increases in recurrent traumas. Rosen et al. [12] detected a hospitalization rate of $8 \%$ in abuse cases. We detected higher rates of hospitalization in victims of abuse (abuse $21.8 \%$, falling $4.8 \%$ ). We believe that trauma patients are usually hospitalized due to higher violence severity in abuse cases. Since the patients referred to hospital even for simple injuries in other trauma cases, the rate may be lower due to discharge of the patients without severe pathology.

Higher morbidity and mortality rates in elder abuse cases are associated with delays in detection [12]. It was previously stated that $t$ severity of the traumas increases as a result of elder abuse and this may cause mortality [24]. The mortality rate due to elder abuse was reported $6 \%$ to $18.13 \%$ [6]. Kara et al. [25] reported that 5\% of the elder patients exposed to trauma have died. Rosen et al. [12] detected a hospitalization rate of $1 \%$ in abuse cases. Schofield et al. [26] detected a death rate of $23.6 \%$ in elder abuse. Although the mortality rate of the abuse victims was detected higher (7.9\%) when compared with falling, the difference was not statistically significant. Trauma location of the patients who have died was similar with those who survived; however, higher ISS and lower GCS were detected in the patients who have died. There was not any statistically significant difference between patients survived and deceased for trauma location; however, ISS, GCS were higher in deceased cases. We considered that abdominal and thoracic traumas appeared on the patients who were aggressively battered, limited physiological reserves after hospitalization and concomitant infections may cause death. Furthermore, the patients abused are not taken to the hospital because of minor injuries; therefore, this may have increased hospitalization and mortality rates. Higher GCS scores, persistent trauma on the head and higher ISS in mortal patients may have shown that trauma have caused irreversible damage in mortal patients.

The most significant limitation of the present study was data loss due to retrospective design of the study, and not registering some cases as forensic case. Another limitation was not excluding the actual assault cases among the patients admitted because of falling, and lack of an exact exclusion since some scenarios correspond to the scenario of falling. Another limitation of this study was lower number of the cases when compared to the control group. The basic cause for that was the effort to detect an adequate ratio $(1 \% / 10)$ and possible ignorable situations (i.e., comorbidity, the prevalence of trauma location) in the control group while including all cases of the patient group. However, we believe that the importance of the difference between the case and control groups since comparisons of the parameters were performed according to the column ratios. One of the limitations is not benefiting from forensic medicine department during and after emergency clinic evaluation.

Abuse causes severe traumas when compared with accident and falling. The probability of abuse should be considered in elder trauma cases with specific locations (upper limbs and face etc.). 


\section{AUTHOR CONTRIBUTIONS}

$\mathrm{KC}$ and TC designed the study. TC collected the data. $\mathrm{KC}$ analyzed the data. $\mathrm{KC}$ and $\mathrm{TC}$ analyzed the results and drafted the manuscript.

\section{ETHICS APPROVAL AND CONSENT TO PARTICIPATE}

The study was following approval of local ethical committee of Abant Izzet Baysal University (Date: 21/01/2020; Decision No: 2019/248).

\section{ACKNOWLEDGMENT}

We would like to thank the hospital staff who contributed to our study and the participants who agreed to participate.

\section{FUNDING}

This research received no external funding.

\section{CONFLICT OF INTEREST}

The authors declare no conflict of interest.

\section{REFERENCES}

[1] Switzer JA, Michienzi AE. Elder abuse: an update on prevalence, identification, and reporting for the orthopaedic surgeon. The Journal of the American Academy of Orthopaedic Surgeons. 2012; 20: 788-794.

[2] Evans CS, Hunold KM, Rosen T, Platts-Mills TF. Diagnosis of elder abuse in U.S. emergency departments. Journal of the American Geriatrics Society. 2017; 65: 91-97.

[3] Murphy K, Waa S, Jaffer H, Sauter A, Chan A. A literature review of findings in physical elder abuse. Canadian Association of Radiologists Journal. 2013; 64: 10-14.

[4] Statistics Canada. Family violence in Canada: a statistical profile. 2009. Available at: http://www.statcan.gc.ca/pub/85-224-x/ 85-224-x2010000-eng.pdf (Accessed: 20 December 2019).

[5] Kılıç Öztürk Y, Düzenli E, Karaali C, Öztürk F. Physical violence among elderly: analysis of admissions to an emergency department. Turkish Journal of Trauma \& Emergency Surgery. 2017; 23: 56-60.

[6] Dong X, Simon M, De Leon CM, Fulmer T, Beck T, Hebert L, et al. Elder self-neglect and abuse and mortality risk in a community-dwelling population. The Journal of the American Medical Association. 2009; 302: 517-526.

[7] Stevens TB, Richmond NL, Pereira GF, Shenvi CL, Platts-Mills TF. Prevalence of nonmedical problems among older adults presenting to the emergency department. Academic Emergency Medicine. 2014; 21: 651658.

[8] Gowland RL. Elder abuse: evaluating the potentials and problems of diagnosis in the archaeological record. International Journal of Osteoarchaeology. 2016; 26: 514-523.

[9] Acierno R, Hernandez MA, Amstadter AB, Resnick HS, Steve K, Muzzy
W, et al. Prevalence and correlates of emotional, physical, sexual, and financial abuse and potential neglect in the United States: the national elder mistreatment study. American Journal of Public Health. 2010; 100: 292-297.

[10] Rosen T, Bloemen EM, Harpe J, Sanchez AM, Mennitt KW, McCarthy $\mathrm{TJ}$, et al. Radiologists' training, experience, and attitudes about elder abuse detection. American Journal of Roentgenology. 2016; 207: 12101214.

[11] Gironda MW, Nguyen AL, Mosqueda LM. Is this broken bone because of abuse? Characteristics and comorbid diagnoses in older adults with fractures. Journal of the American Geriatrics Society. 2016; 64: 16511655.

[12] Rosen T, Bloemen EM, LoFaso VM, Clark S, Flomenbaum NE, Lachs MS. Emergency department presentations for injuries in older adults independently known to be victims of elder abuse. The Journal of Emergency Medicine. 2016; 50: 518-526.

[13] Cham GW, Seow E. The pattern of elderly abuse presenting to an emergency department. Singapore Medical Journal. 2000; 41: 571-574.

[14] Tanrıkulu C, Tanrıkulu Y. Geriatrik popülasyonda travma analizi: kesitsel çalışma. Yeni Tıp Dergisi. 2013; 30: 100-104. (In Turkish)

[15] Santos CMD, De Marchi RJ, Martins AB, Hugo FN, Padilha DMP, Hilgert JB. The prevalence of elder abuse in the Porto Alegre metropolitan area. Brazilian Oral Research. 2013; 27: 197-202.

[16] Frazão SL, Silva MS, Norton P, Magalhães T. Domestic violence against elderly with disability. Journal of Forensic and Legal Medicine. 2014; 28 : 19-24.

[17] Lachs MS, Pillemer K. Elder abuse. Lancet. 2004; 364: 1263-1272.

[18] Dong X, Simon MA. Association between elder self-neglect and hospice utilization in a community population. Archives of Gerontology and Geriatrics. 2013; 56: 192-198.

[19] Dong XQ. Elder abuse: systematic review and implications for practice. Journal of the American Geriatrics Society. 2015; 63: 1214-1238.

[20] Kaldirim U, Tuncer SK, Ardic S, Tezel O, Eyi YE, Arziman I, et al. Analysis of elderly patients presenting to the emergency department via ambulance. Turkish Journal of Emergency Medicine. 2013; 13: 161-166.

[21] Fisher BS, Regan SL. The extent and frequency of abuse in the lives of older women and their relationship with health outcomes. The Gerontologist. 2006; 46: 200-209.

[22] Kandiş H, Karakuş A, Katirci Y, Karapolat S, Kara IH. Geriatric population and forensic traumas. Turkish Journal of Geriatrics. 2011; 14.

[23] Abath MDB, Leal MCC, Melo Filho DAD, Marques APDO. Physical abuse of older people reported at the Institute of Forensic Medicine in Recife, Pernambuco State, Brazil. Cadernos de Saúde Pública. 2010; 26 : 1797-1806.

[24] Wong NZ, Rosen T, Sanchez AM, Bloemen EM, Mennitt KW, Hentel K, et al. Imaging findings in elder abuse: a role for radiologists in detection. Canadian Association of Radiologists Journal. 2017; 68: 16-20.

[25] Kara H, Bayir A, Ak A, Akinci M, Tufekci N, Degirmenci S, et al. Trauma in elderly patients evaluated in a hospital emergency department in Konya, Turkey: a retrospective study. Clinical Interventions in Aging. 2014; 9: 17-21.

[26] Schofield MJ, Powers JR, Loxton D. Mortality and disability outcomes of self-reported elder abuse: a 12-year prospective investigation. Journal of the American Geriatrics Society. 2013; 61: 679-685.

How to cite this article: Kaan Celik, Tamer Colak. The comparison of assault and falling in elder patients over 65 years of age. Signa Vitae. 2021;17(6):131-135. doi:10.22514/sv.2021.090. 